\title{
Assessment of the left ventricle in adult athletes
}

\author{
Bahaaedin A. Elkhader*, Abdullah 0. Alamoudi
}

Department of Radiological Science and Medical Imaging, College of Applied Medical Sciences, Majmaah University, Riyadh, Saudi Arabia

\section{ARTICLE INFO}

\section{Article history:}

Received 9 February 2017

Received in revised form

23 March 2017

Accepted 26 March 2017

\section{Keywords:}

Sport

Structural changes

Dimensions

\begin{abstract}
A B S T R A C T
Competitor's heart is a set of constructions and physiological alteration that correlate to a long period of sport. The lack of reference to this status may lead to be classified as a disease, this study intended to evaluate morphological and functional changes in left ventricular in male athletes. One hundred and thirty-one intact participants between 15-33 years were involved in this research, 31 of them act as a control subject, echocardiographic scan was done to find left ventricular internal enddiastolic dimension, interventricular septal wall thickness, left ventricular posterior wall thickness, relative wall thickness, left ventricular mass and ejection fraction for two groups of athletes (aerobic \& anaerobic) and nonsports group (control), analysis was conducted using SPSS (Statistical Package for the Social Sciences). Athlete's average parameters were higher than those of the control were; end diastolic dimension $(51.5 \pm 4.8 \mathrm{~mm}$ versus $48.0 \pm 4.4 \mathrm{~mm})$, interventricular septal wall thickness $(9.7 \pm 1.05 \mathrm{~mm}$ versus $8.4 \pm 0.9 \mathrm{~mm})$, posterior wall thickness $(9.5 \pm 0.85 \mathrm{~mm}$ versus $8.4 \pm 0.6 \mathrm{~mm})$, relative wall thickness $(0.40 \pm 0.08 \mathrm{mmversus} 0.35 \pm 0.05 \mathrm{~mm})$, left ventricular mass $(191.1 \pm 37.2 \mathrm{~g}$ versus $141.1 \pm 36.4 \mathrm{~g})$ and ejection fraction $(70.6 \pm 5.3$ versus $66.5 \pm 4.5$ ). There was a significant difference between athletes and the control participants concern to all measurements. Results of the study are compatible with earlier findings; this data will be benefit into medical evaluation purpose in the sporty society.
\end{abstract}

(C) 2017 The Authors. Published by IASE. This is an open access article under the CC BY-NC-ND license (http://creativecommons.org/licenses/by-nc-nd/4.0/).

\section{Introduction}

A living without diseases is the people basics. Therefore, all efforts made to fight sickness to prevent it from happening instead of treatment processes (Khatun and Bandyopadhyay, 2016).

Physical activity was classified in sets according to some factors, included exist of oxygen, and type of exercise, the new alterations of the heart tissue differ relying to the activity kind (Lavie et al., 2001).

Exercise for long periods and regularly leads to the occurrence of structural and functional changes in the organs of the body in general and the heart in particular, which requires adaptation of the body with it (Shihab et al., 2016). Most of researchers focused their efforts In study the changes occur in the heart of sport person (Rawlins et al., 2009). The increase in the dimensions of the left ventricle is a feature of the heart in practitioners' sports (Engel et

\footnotetext{
* Corresponding Author.

Email Address: b.elkhader@mu.edu.sa (B. A. Elkhader) https://doi.org/10.21833/ijaas.2017.05.019

2313-626X/C 2017 The Authors. Published by IASE.

This is an open access article under the CC BY-NC-ND license

(http://creativecommons.org/licenses/by-nc-nd/4.0/)
}

al., 2016). In the twentieth century, it has been identified on the strong correlation between the human body measurements and achievement (Prakash and D'Souza, 2016). Today, echo represents the best choice of heart imaging (Elkhader et al., 2014), by using its capacity of detecting anatomy, physiology and pathology of the heart were progress, especially with three -dimension (D'Andrea et al., 2015). Only few studies have evaluated the changes in the left ventricle after exercise in different groups of athletes (Legaz et al., 2005).

\section{Materials and methodology}

This a Case-Control Study includes a sum of one hundred participants aged 15-33 years who practiced various types of sports( 50 bodybuilding as anaerobic and 50 swimmers as aerobic ), thirty-one healthy males, free from any heart and other diseases similar age and unsporting represented the control set. Sufficient information and unwritten approval were collected before carrying out ultrasound scan. All procedures and research aims were illustrated to participants and their data kept in full confidentiality Echocardiography examination 
was achieved using Aloka SSD-5000 ultrasound system, with $2.5 \mathrm{MHz}$ UST-5297 Phased probe. Ultrasound was done in the recumbent position, the probe was put between ribs; move in various directions to get suitable images. Distinguishing movement differentiated return waves; frontal and backward motions indicated left ventricular contraction and dilatation, Respectively (Elkhader et al., 2014).

The following measurements have taken from echocardiographic examination:

1- LV end diastolic dimension, mm (LVEDD)

2- Interventricular septal wall thickness, mm (IVS)

3-Left ventricular posterior wall thickness, $\mathrm{mm}$ (PWT)

4- Relative Wall Thickness, mm (RWT) ([IVS+ PWT]/ LVEDD)

5-Left ventricular mass,g (LV mass) (ASE method) (Eq. 1)

$=0.8(1.04([$ LVEDD+PWTD+IVSTD $] 3-[$ LVEDD $] 3))+0.6 \mathrm{~g}$.

6- Ejection fraction (\%) (Simpson rule) (Eq.2)

$\mathrm{EF}(\%)=[(\mathrm{EDV}-\mathrm{ESV}) / \mathrm{EDV}] \times 100$

Significance of this study was examined by using $t$ test.

\section{Results}

Primary information for both athletes and control displayed was shown in Table 1. Body mass index of participants was higher in athletes' participants than control.

Echo values of the left ventricle of subjects and controls demonstrated in Table 2. There were considerably higher and a notable variation in all $\mathrm{Lv}$ parameters [LVEDD, IVS , PWT, RWT, LV mass and the ejection fraction of the sportsperson in comparison to non-sportsperson (controls)].

In the athletes the utmost value of LVEDD was 62 $\mathrm{mm}$. More than $58 \mathrm{~mm}$ found in three athletes.

There was a remarkable variation between aerobic and anaerobic athletes with respect to all $\mathrm{Lv}$ parameters except relative wall thickness and ejection fraction which did not represent a significant difference $(\mathrm{P}>0.05)$.

\section{Discussion}

Sports have many benefits for people in their daily lives in terms of their contribution to develop of physical fitness, the social aspect and the functionality of the individual (Merkel, 2013).

Human body measurements and the features of heart and its blood vessels for athletes is one of the fundamentals of the coaching and effective factor for excellence, as stated in the study carried out by Kyselovičová et al. (2016).

The dominant characteristic of the heart of the sports person is a functional increase in size. There is a distinct enlarge in the dimensions of the left ventricle for practitioners of sports, compared with the control group. In this study 11 of 100 athlete participants show an increase in left ventricle enddiastolic dimension $(<58 \mathrm{~mm})$.

Table 1: Age and BMI of participants

\begin{tabular}{cccc}
\hline variable & Athletes $(\mathrm{n}=100)$ & Control $(\mathrm{n}=31)$ & P value \\
\hline Age $(\mathrm{year})$ & $22.04 \pm 3.9$ & $20.7 \pm 4.6$ & 0.29 \\
BMI $\left(\mathrm{kg} / \mathrm{m}^{2}\right)$ & $23.09 \pm 3.4$ & $22.8 \pm 3.8$ & 0.83 \\
\hline
\end{tabular}

Table 2: Echocardiographic data of left ventricle

\begin{tabular}{|c|c|c|c|}
\hline \multirow{2}{*}{ Variable } & \multicolumn{2}{|c|}{ Athletes } & \multirow{2}{*}{ Control } \\
\hline & Anaerobic & Aerobic & \\
\hline LVEDD (mm) & $52.8 \pm 4.6 * f$ & $50.2 \pm 5.0 ` \Omega$ & $48.0 \pm 4.4$ \\
\hline IVS (mm) & $10.2 \pm 1.2^{*} \gamma$ & $9.1 \pm 0.9 \quad \#$ & $8.4 \pm 0.9$ \\
\hline PWT (mm) & $10.0 \pm 0.9^{*} \gamma$ & $9.0 \pm 0.8 *$ & $8.4 \pm 0.6$ \\
\hline RWT (mm) & $0.44 \pm 0.09 *$ & $0.41 \pm 0.07$ * & $0.35 \pm 0.05$ \\
\hline LV mass(g) & & & \\
\hline $\begin{array}{c}\text { [ASE } \\
\text { method] }\end{array}$ & $201.8 \pm 42.4$ * $f$ & $180.4 \pm 32.0$ * & $141.1 \pm 36.4$ \\
\hline $\begin{array}{c}\text { Ejection } \\
\text { fraction (\%) }\end{array}$ & $69.7 \pm 5.8 \#$ & $71.4 \pm 4.8^{*}$ & $66.5 \pm 4.5$ \\
\hline
\end{tabular}

Left ventricle end-diastolic dimension, interventricular septal wall thickness, left ventricular posterior wall thickness, relative wall thickness, Left ventricular mass and ejection fraction have a considerable increase in athlete groups in compare to control persons. Reference to BMI both groups in the normal range. Numerous studies have shown the same results of the current study.

The study carried out by Venckunas detected that there is a close correlation between the increase in the size of the heart and exercise (Venckunas et al., 2011).

This study found that there were considerable differ between aerobic and anaerobic athletes in most parameters.

In comparison with ordinary mature, basketball players have grand left ventricle, a similar result was found in participants in various sport activities (Engel et al., 2016).

\section{Conclusion}

This research was designed to examine the effect of sport in human organs (heart), the results of this study do not go far from the preceding one. This study has exhibited important changes in left ventricle dimensions after physical exertion, such as in different researches around the world. It is necessary to differentiate normal changes from abnormal situations. Using of echocardiography system help in detecting any cardiac reconstruction due to physical activity. These outcomes should put in mind at the beginning of any new research project. Further studies, should deal with individuals of the same age, gender and race.

\section{References}

D'Andrea A, Bossone E, Radmilovic J, Caso P, Calabrò R, and Russo $M$ (2015). The role of new echocardiographic techniques in athlete's heart. US National Library of Medicine, National 
Institutes of Health, F1000Research. Available online at: https://www.ncbi.nlm.nih.gov/pmc/articles/PMC4654447/

Elkhader B, Bala A, Ali Omer M (2014). Assessment of ejection fraction in myocardial infarction patients after the use of betablockers. International Journal of Advanced Research in Biological Sciences, 1(7): 30-35.

Elkhader BA, Abdulla AA, Ali Omer MA, Fagiri MA, and Mahmoud MZ (2014). The impact of obesity on the left ventricular ejection fraction using echocardiography. Open Journal of Medical Imaging, 4(4): 172-177.

Engel D, Schwartz A, and Homma S (2016). Athletic cardiac remodeling in US professional basketball players. JAMA Cardiology, 1(1): 80-87.

Khatun A and Bandyopadhyay N (2016). An evaluation of health awareness and physical education programme of different category of secondary school in West Bengal. International Journal of Physical Education, Sports and Health. 3(3):624626.

Kyselovičová $\mathrm{O}$, Labudová J, Zemková E, Čierna D, and Jeleň M (2016). Anthropometric and cardiovascular variables of elite athletes. Acta Facultatis Educationis Physicae Universitatis Comenianae, 56(2): 143-158.

Lavie CJ, Milani RV, Marks P, de Gruiter H (2001). Exercise and the heart: Risk, benefits, and recommendation for providing exercise prescriptions. The Ochsner Journal, 3(4):207-212.
Legaz A, González M, and Lacambra I (2005). A follow-up study of the changes in left ventricle and running performance in highly trained runners. Biology of Sport, 22(2): 135-149.

Merkel DL (2013). Youth sport: Positive and negative impact on young athletes. Open Access Journal of Sports Medicine, 4: 151-160.

Prakash C and D'Souza G (2016). Comparative study of anthropometric indices among swimmers and non-swimmers. International Journal of Physical Education, Sports and Health, 3(2):182-183.

Rawlins J, Bhan A, and Sharma S (2009). Left ventricular hypertrophy in athletes. European Journal of Echocardiography, 10(3): 350-356.

Shihab H, AlMosawi S, and Hamza A (2016). Using falling (deep) jump training units to improve the explosive and characterized by speed forces for the badminton players. Indian Journal of Research, 5(10): 206-208.

Venckunas T, Vasiliauskas D, Marcinkeviciene J, Grizas V, Stasiulis A, and Malkova D (2011). Strongmen sport is associated with larger absolute heart size and impaired cardiac relaxation. Journal of Strength and Conditioning Research, 25(10): 29192925. 